\title{
Impact of Cooling Strategies on Energy Reduction
}

\author{
Nadia Al-Badri', Hanan Taleb ${ }^{2}$ \\ ${ }^{1}$ Interiors and Architecture Department, Sharjah, University of Sharjah \\ UAE \\ nalbadri@sharjah.ac.ae \\ ${ }^{2}$ Sustainable Design Building Environment, Dubai, British University in Dubai \\ $\mathrm{UAE}$ \\ hanan.taleb@buid.ac.ae
}

\begin{abstract}
Passive design has acquired great importance due to the increase in living standard and energy consumption .Passive design architecture approach aims to use of specific building design principles to minimize the energy requirements to achieving thermal comfort. There are several parameters, which can affect passive design criteria like, thermal comfort, climate condition, orientation, building's shapes and opening, types of sunshade, selected materials, vegetation etc. All these parameters can integrated or used separately to achieve the goal of passive concept. In many instance, the design approach neglected these parameters in order to create new contemporary concept of design building. The paper explores part of thermal cooling strategies to achieve energy reduction. The motive was to reduce depending on energy by using passive strategies and evaluated through using modelling simulation due to design phase. Simulation methodology was used to carry out this study using IES-VE software to model the energy consumption, calculate, and evaluate the power consumption and energy saving, thermal comfort and $\mathrm{CO} 2$ emission . Purpose of the study is to identify and highlight the main passive design cooling strategies by using them in design concept. The major part of the simulations is the thermal analysis because it has a significant important to locate the building performance in comfort zone, minimizing the energy consumption and $\mathrm{CO} 2$ emission. The integration between many strategies can achieve high level of building performance to provide solutions and evaluated the impact of each one on energy consumption and building performance.
\end{abstract}

Keywords: cooling strategies, IES simulation, hot climate, Energy reduction

\section{Introduction}

The term passive design, defines as a series of architectural design strategies used by the architectural and designer to develop buildings to respond adequately to climatic conditions among other contextual necessities. Over last decade, rapid growth in economic and population accompanied with depletion of the energy resources lead to serious impacts on environment and humanity. This development coupled with active constructions, which in some examples ignore the impact on environment and human activities. In developing countries, it seems that there is a huge gap between the current construction practices and sustainable principle, which need more attention to clarify and define the problems in order to find suitable solutions before it comes more difficult and expensive. Buildings sectors consumes $40 \%$ of the world energy while it is responsible for $50 \%$ of the $\mathrm{CO} 2$ emissions [1].

\section{Aim of the Study}

The study aims to design a building in terms of passive deign strategies and performance through testing and analysing data by using computer simulation. The purpose of the study is to identify and highlight the main passive design cooling strategies by tested them in design phase.

\section{Methodology}

The research methods is IES Virtual Environment program which is a performance analysis software allows architects and engineers to offering quantitative feedback provides an integrated collection application that can easily linked by a single integrated data model and a common user interface. IES program coupled with green building concept can achieved $30 \%$ less energy used than conventional buildings. In addition, it assists in showing the LEED and BREEAM 
regulation and producing UK energy Performance Certificate. It consists many different modules, each one offering specific calculation such as "ModelIT" to modelling the space "Radiance" for lighting simulation, "SunCast" for simulating solar shading device, "Apache Sim" for thermal simulation analysis and CFD for airflow simulation, also it used "Mechanical" for mechanical simulation.

\section{Climate by Ecotect Weather tools Analysis}

The sun position in Dubai can determine the general climate as shows in figure 1 which is generally hot and dry. The temperature reaches to $48 \mathrm{C}$ in summer, as it is clear from the weekly summary in figure 2 July and August are the hottest moths of the year combined with the high level of humidity which can be soar to 80 or sometime it could be more. These figures have been generated by Ecotect weather tools.

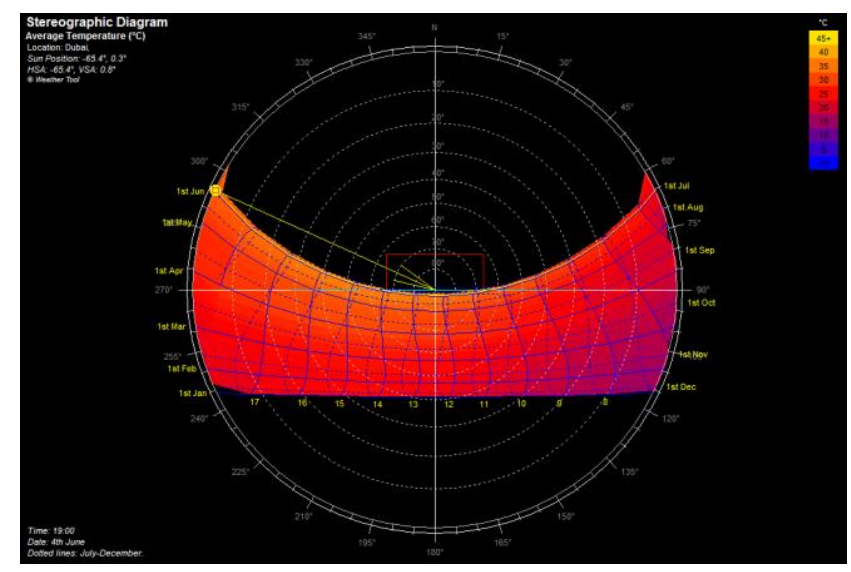

Fig. 1: Sun path in Dubai, generated, by Ecotect.

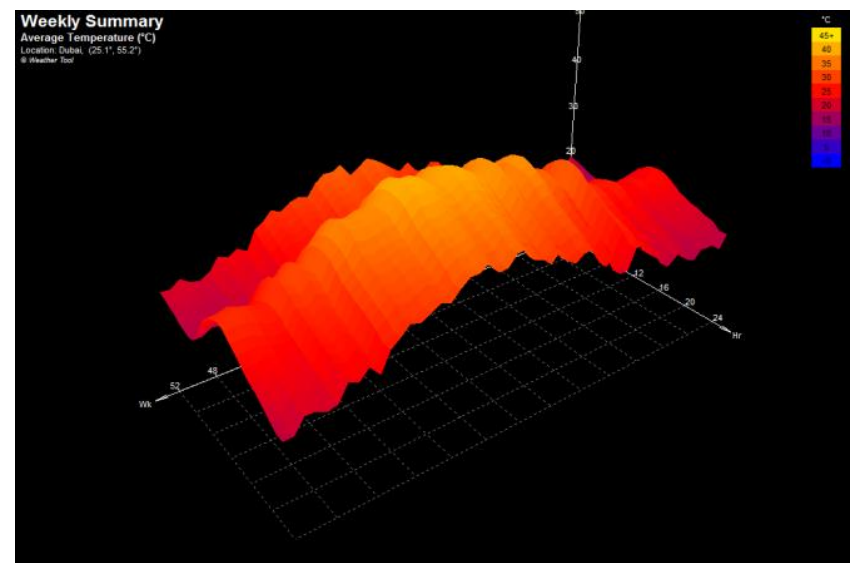

Fig. 2: Weekly summer temperature generated, by Ecotect.

\subsection{Comfort Zone Analysis}

The main goal of the passive design is to achieve the climate and comfort for any building, which means that the human will feel comfortable in the building according to local climate. In order to feel comfortable there are many parameters should be available to provide this feeling. Developing countries people spend approximately $90 \%$ of their time indoor thus, it is very significant to identify the major factors that affect the indoor environment of inhabitants in their homes and determine the person's behaviour that may influence their comfort [3] [4]. It is very clear from the Psychometric chart below that in summer the comfort zone not align with the climate while in winter it shows that the comfort zone be more matching with the climate as explain in figure 4 and figure. 5 There are major factors affect the level of thermal comfort, such as, air temperature, air humidity, air velocity, radiant temperature, human activity types, levels, and human clothing level. All these factors determine the heat balance of human body and give the indication of the thermal comfort level in the space [3]. 


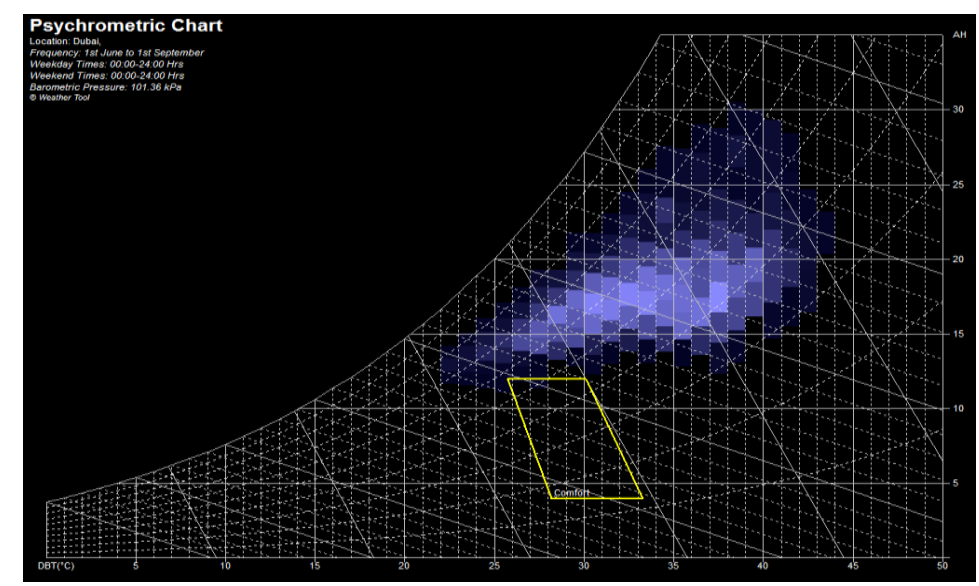

Fig. 3: Psychometric Chart of comfortable zone summer.

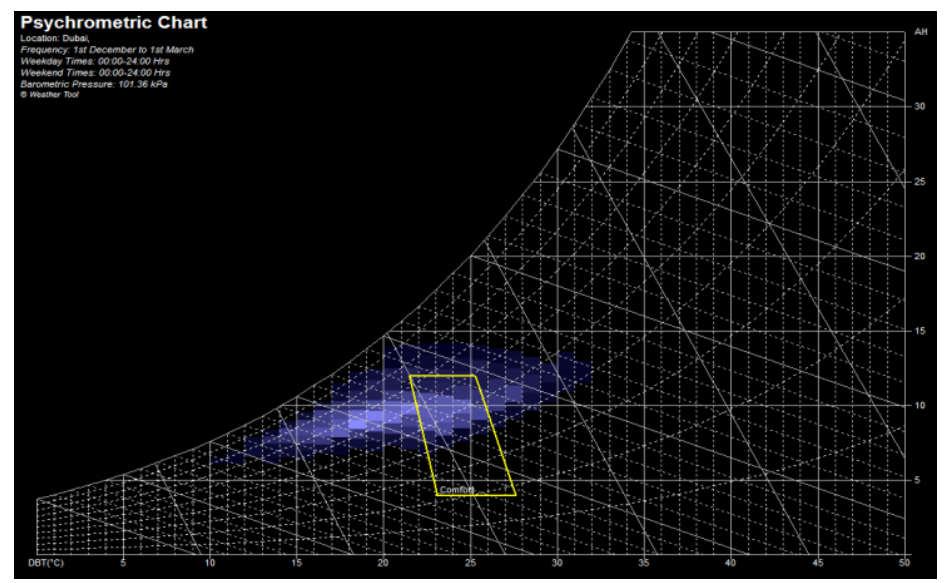

Fig. 4: Psychometric Chart of comfortable in winter.

\section{Passive Cooling Design Strategies}

There are many major strategies, that are still affected the design to achieve the passive design. The paper selectd the most effected stratiges in hot climate which are as the follwings

\subsection{The used of the courtyard}

Over many centuries and nowadays the courtyard present, the most characteristic forms of residential architecture in hot climates in order to utilized it as a source of shade and ventilation in daytime and as a collector for the cool air at night. It had been conclude that the courtyard building could be relevant in all climates but it was more energy efficient in hot dry and hot-humid climates than temperate and cold climates [5]. Traditional courtyard represented the focus point to provide the natural ventilation and day lighting to the entire spaces. The main factors that affect the level of thermal performance of the courtyard mainly are the glazing type, percentage for the courtyard walls and building height. It has been concluded that in a hot humid climate, the total energy consumption was less by $45 \%$ compared with a cold climate in a courtyard having double low-e (double-glazed window with a high-solar gain low-E glass with argon gas fill, these windows are designed to reduce solar gain) with $67 \%$ glazing surface area. While In a hot-humid climate, the total energy consumption was less by $23 \%$ compared with the same courtyard in a cold climate when it the courtyard having triple clear glass with $30 \%$ glazing surface area.

\subsection{Insulation Materials}

Insulation is the significant factor that can affect energy performance of buildings, through providing resistance to heat flow. Thermal mass can be achieve in building through the kind of materials and the type of insulation that used, when 
the materials have low $\mathrm{U}$ value, thus it will be provide the building with high level of insulation. In traditional building the major materials that have been used were, the burned brick and the wood, the thick external wall with the attached building can create a thermal mass although of the limited variety and technology in that days [6].

\section{Simulations}

A case study of regular plan with a courtyard have been selected to test in the simulations. The main phase of the IES is the Model IT which provide with simple way to build your model with high level of controlling dimensions and located the opening ( door and windows) in professional ways by determine the ratio of the opening. In order to be sure that your model working probably, the 3D model could be check during the modelling.

\subsection{Courtyard used strategy (Apache Simulation)}

The major part of the simulations are depending on thermal analysis because it has a significant important to locate buildings performance in comfort zone and minimize the energy consumption by reducing the air-conditioning used. Figure 5 represents a chart data shows courtyard performance through comparison between used of courtyard (green) and without courtyard (red) assumed, AC is off during hottest month of the year which is August. The second Apache simulation considered that building occupied for specific time so, air- conditioning will be on from 9am-5pm recognizing difference in courtyard used and un sued in August as seen in figure 6. While Figure 7 shows different in temperature between used of courtyard or not in August ,the most hot moth in the country.

\subsection{Insulation Materials strategy (Apache Simulation)}

The used of insulation is conclusive to reduce the energy demand which lead to minimize the $\mathrm{CO} 2$ emissions, the result shows that the energy reductions up 64\% in summer Figure 8 shows comparing between case that using low UValue materials and common materials during the hottest month in UAE, August.

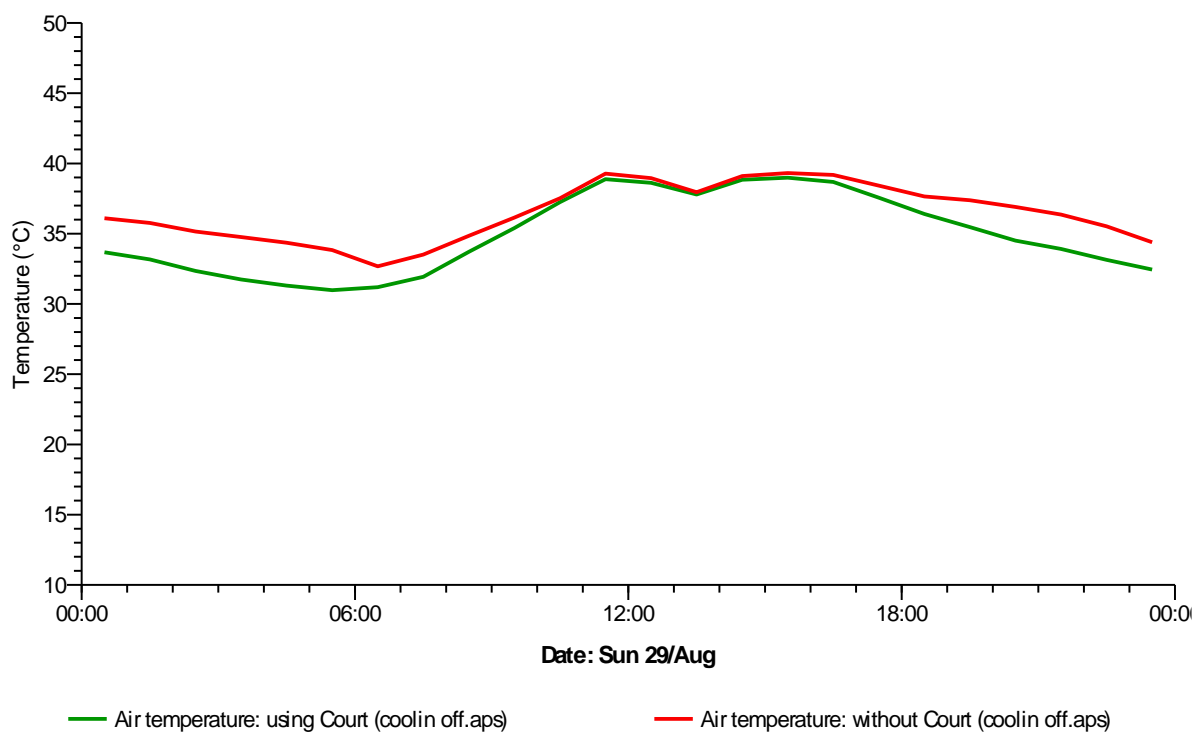

Fig. 5: Shows comparing, between courtyard used (green) and without (red), AC off in August. 


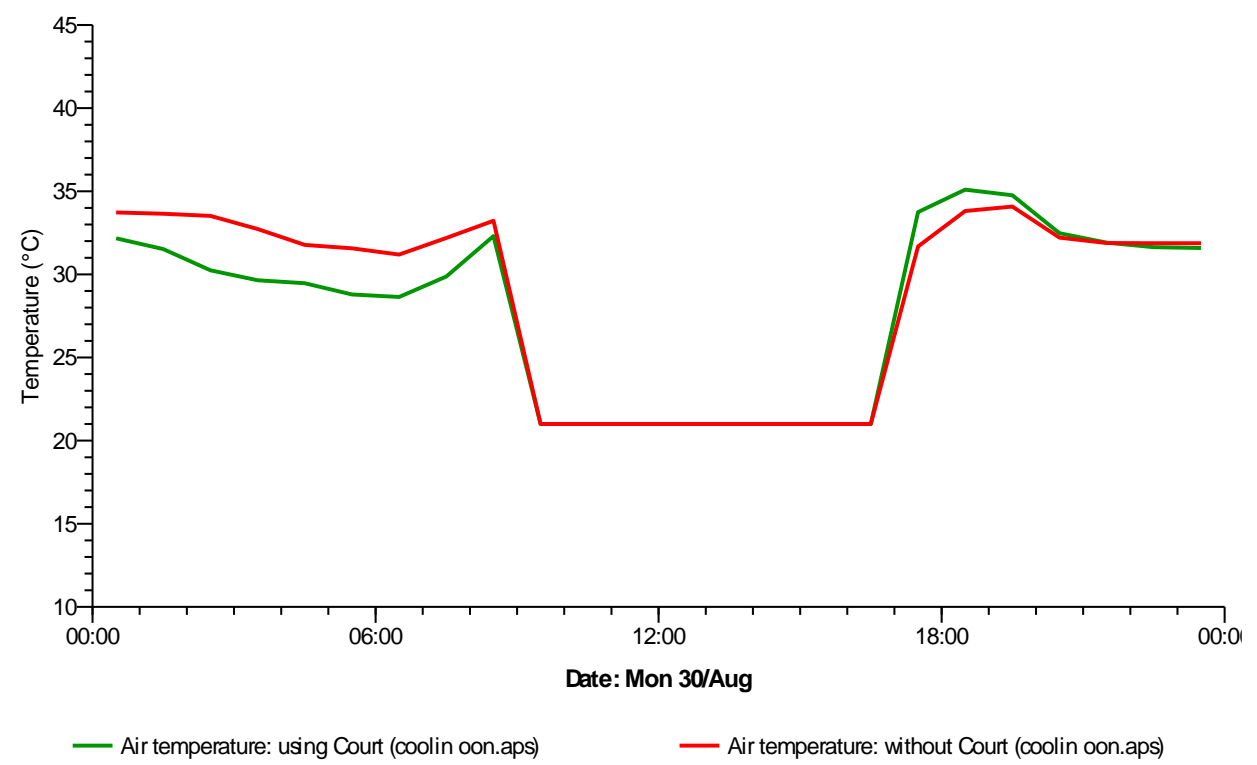

Fig. 6: Shows different temperature between courtyard used and without, in August considering limited time of Occupancy and AC On.

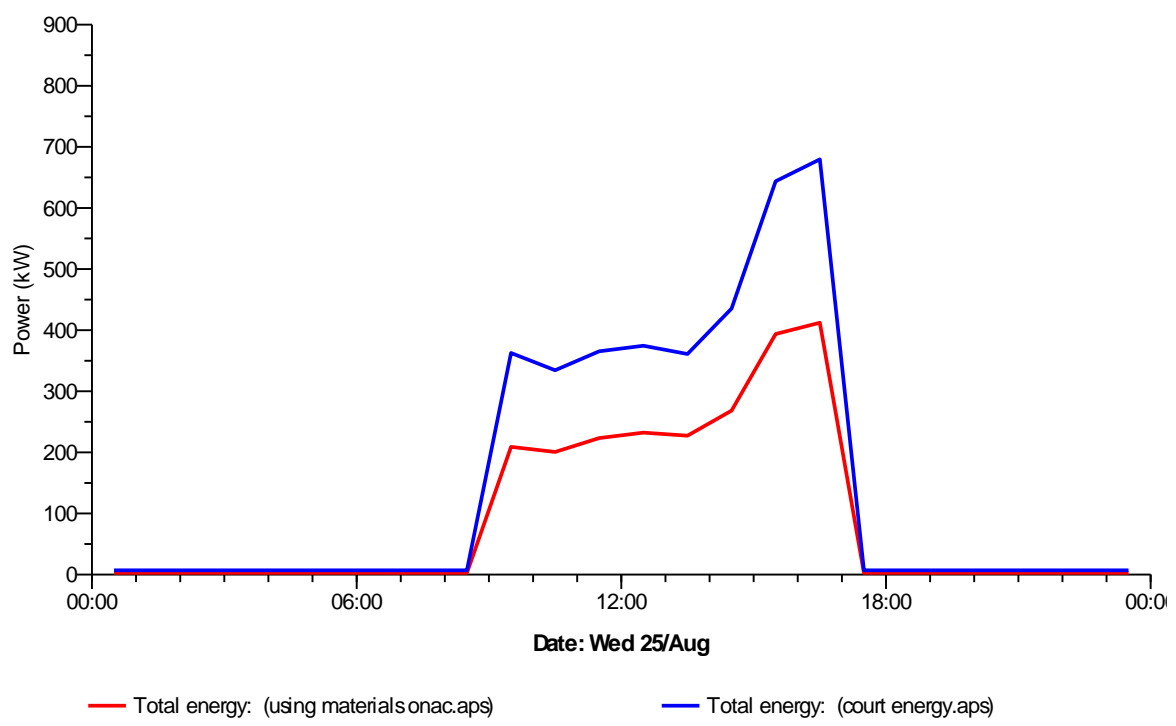

Fig. 7: Shows the different in total energy when used Low U-Value insulation materials in August. 


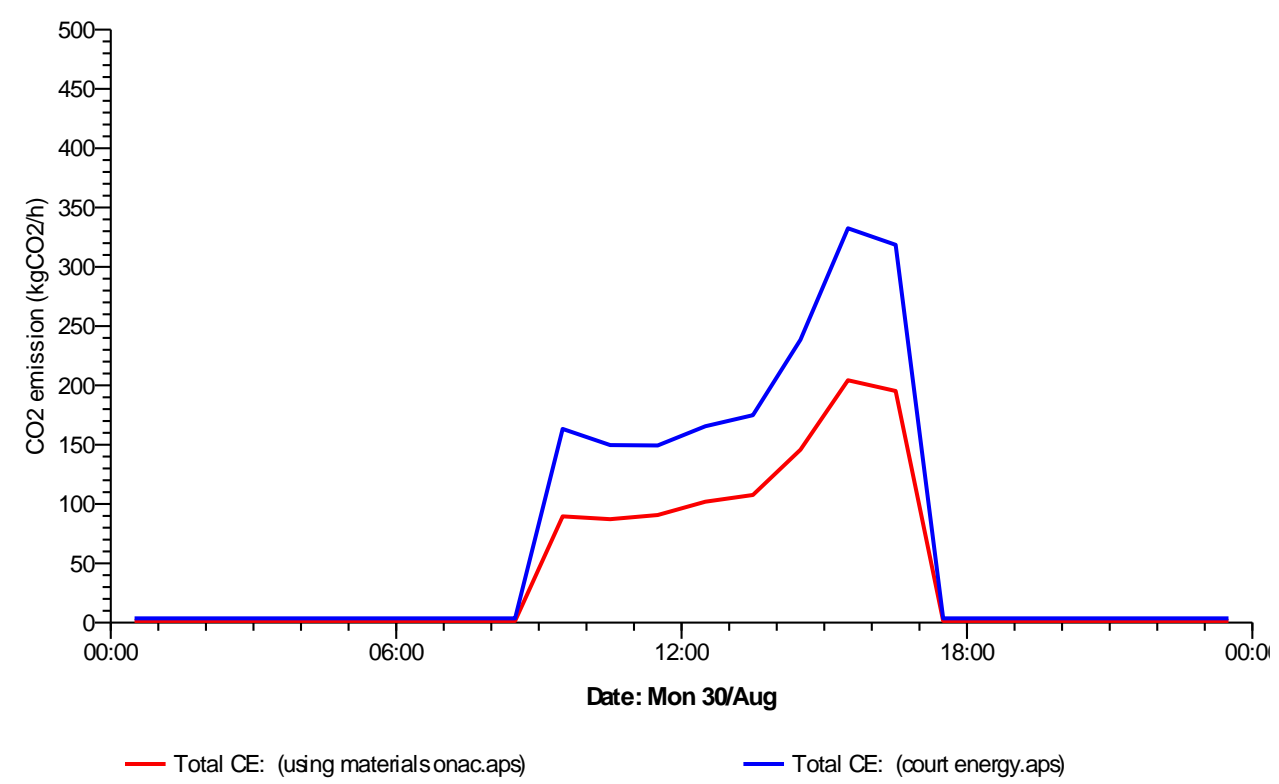

Fig. 8: Shows CO2 emission for low U-Value insulation materials and common materials in August.

It is clear that the thermal performance is the main parameters of the simulation. The used of the courtyard have $3 \mathrm{C}$ less than the building without courtyard. As the temperature is almost high in Dubai the air- conditioning should be working over the year, so this will affect the total amount of energy consumption. While the selection of materials can be determine the level of insulation for the building. The discussion above clarifies that the passive cooling strategies can reduce the temperatures, which lead to minimize the energy consumption and $\mathrm{CO} 2$ emission. The integration between many strategies can achieve high level of building performance.

\section{Conclusion}

The investigation through simulations clarify that passive cooling strategies can reduce temperatures, which lead to minimize the energy consumption and $\mathrm{CO} 2$ emission. Integration between many strategies can achieve high level of building performance. Computer simulation methodology can achieve many advantages such as; the flexibility to provide measurement at any time and any sessions of the year. It also can changing the parameters easily with limited time, comparison can be done between many cases or comparing with standards, the simulation can be run several times to be sure of accuracy level . In addition to that, building modelling can easily done with minimum time and effort considering different weather data and locations. Thus the scale and orientation can be change in any stage of the simulation. On the other hand, computer simulation still has validation problems and inaccurate results while applying the weather data or during the modelling, stage [7].It has been found that passive cooling design strategies affected buildings performance; meanwhile these strategies represent simplest ways and lower cost options that could improve cooling level inside buildings. As mention before buildings sectors consumes $40 \%$ of the world energy while it is responsible for $50 \%$ of the $\mathrm{CO} 2$ emissions, which required of optimal improvement in cooling building performance, air - conditioning used will be less which reduce energy consumption. Energy reduction lead to reduce $\mathrm{CO} 2$ emission, all these can be achieve by adapted passive design strategies that can examine during design phase, tested by computer simulations.

\section{References}

[1] C. Ochoa, I. Capeluto, "Strategic decision-making for intelligent buildings: Comparative impact of passive design strategies and active features in a hot climate," Building and Environment, vol. 43, pp. 1829-1839, 2008.

[2] L. F. Cabeza, A. Castell, M. Medrano, I. Matorell, G. Perez, I. Fernandez, "Experimental study on the performance of insulation materials in Mediterranean Construction," Energy and Buildings, vol. 42, no. 5, pp. 630-636, 2010.

[3] M. Frontczak, R. Andersen, P. Wargocki, "Questionnaire survey on factors influencing comfort with indoor environmental quality in Danish housing," Building and Environment, vol. 50, 2012. 
[4] A. S. Dili, M. A. Naseer, T. Zacharia Varghese, "Thermal comfort study of Kerala traditional residential buildings based on questionnaire survey among occupants of traditional and modern buildings," Energy and Buildings, vol. 42, pp. 2139-2150, 2010.

[5] A. Aldawoud, "Thermal performance of courtyard buildings," Energy and Buildings, vol. 40, pp. 906-910, 2008.

[6] N. Hamza, "Double versus single skin facades in hot arid areas," Energy and Buildings, vol. 40, 240-248, 2008.

[7] Z. Zhai, M. Hall Johnson, M. Krarti, "Assessment of natural and hybrid ventilation models in whole-building energy simulations," Energy and Buildings, vol. 43, pp. 2251-2261, 2011. 